\title{
Oxidative stress inducers potentiate 2,3,7,8-tetrachlorodibenzo-p-dioxin-mediated pre-cardiac edema in larval zebrafish
}

\author{
Katsuki TANAKA ${ }^{1)}$, Hikaru ADACHI ${ }^{1}$, Hironobu AKASAKA ${ }^{1)}$, Junya TAMAOKI'), \\ Yuji FUSE ${ }^{2)}$, Makoto KOBAYASHI ${ }^{2)}$, Takio KITAZAWA ${ }^{1)}$ and Hiroki TERAOKA ${ }^{1 \text { )* }}$ \\ ${ }^{1)}$ School of Veterinary Medicine, Rakuno Gakuen University, Ebetsu, Hokkaido 069-8501, Japan \\ ${ }^{2)}$ Department of Molecular and Developmental Biology, Faculty of Medicine, University of Tsukuba, Tsukuba, \\ Ibaraki 305-8575, Japan
}

J. Vet. Med. Sci.

83(7): 1050-1058, 2021

doi: 10.1292/jvms.21-0081

Received: 14 February 2021

Accepted: 10 May 2021

Advanced Epub:

24 May 2021

\begin{abstract}
We reported the involvement of oxidative stress and prostaglandins including thromboxane and prostacyclin in pre-cardiac edema (early edema) caused by $2,3,7,8$-tetrachlorodibenzo- $p$-dioxin (TCDD). While the involvement of oxidative stress in TCDDinduced toxicity has been frequently reported, the mechanism of its action is still unclear. In the present study, oxidative stress inducers including paraquat, hydrogen peroxide $\left(\mathrm{H}_{2} \mathrm{O}_{2}\right)$ and rotenone augmented early edema (edema) induced by a low concentration of TCDD (0.1 ppb) at $55 \mathrm{hr}$ post fertilization (hpf), while each of them alone did not cause edema. Edema caused by TCDD plus oxidative stress inducers was almost abolished by antioxidants, an antagonist for thromboxane receptor (ICl-192,605) and an agonist for prostacyclin receptor (beraprost), suggesting that the site of action of these inducers was in the regular signaling pathway after activation of aryl hydrocarbon receptor type 2 (AHR2) by TCDD. Oxidative stress inducers also enhanced edema caused by an agonist for the thromboxane receptor (U46619), and the enhancement was also inhibited by antioxidants. Sulforaphane and auranofin, activators of Nrf2 that is a master regulator of anti-oxidative response, did not affect U46619-evoked edema but almost abolished TCDD-induced edema and potentiation by paraquat in both TCDD- and U46619induced edema. Taken together, the results suggest that oxidative stress augments pre-cardiac edema caused by TCDD via activation of thromboxane receptor-mediated signaling in developing zebrafish. As paraquat and other oxidative stress inducers used also are environmental pollutants, interaction between dioxin-like compounds and exogenous source of oxidative stress should also be considered.
\end{abstract}

KEY WORDS: dioxin, edema, oxidative stress, prostaglandin, zebrafish

Polychlorinated dibenzo- $p$-dioxins, dibenzofurans, and coplanar polychlorinated biphenyls (dioxin-like compounds, DLCs) are representative persistent organic pollutants (POPs). Although use of polychlorinated biphenyls (PCBs) was banned from 1960s, these are still serious threats to humans and animals, as these are widely distributed in the environment [43]. DLCs are possible causes of disorders in humans including hypertension, cancer and diabetes [61]. Oxidative stress can damage endothelial cell and increase the permeability to serum, leading to cardiovascular diseases including atherosclerosis and hypertension [3, 28].

It is well known that the aryl hydrocarbon receptor (AHR) is essential for most biological and toxicological responses to DLCs $[7,37]$. AHR is also required for production of oxidative stress by DLCs [36, 51]. It has been frequently reported that toxicological responses by 2,3,7,8-tetrachlorodibenzo- $p$-dioxin (TCDD) and other DLCs are associated with oxidative stress [15]. However, the role of oxidative stress in toxicological responses to AHR agonists is not always clear, including cardiovascular dysfunction. In addition to endogenous source of oxidative stress, hydrogen peroxide $\left(\mathrm{H}_{2} \mathrm{O}_{2}\right)$ are commonly distributed in the river, lake and the sea [60]. Other persistent pollutants including heavy metals and agricultural chemicals (paraquat as a representative example) also are sources of oxidative stress [69].

Zebrafish Danio rerio is now established as a useful in vivo system for toxicological research and tests [16]. The zebrafish is particularly suitable for the research of developmental toxicity by dioxin since the zebrafish embryo is one of the most sensitive organisms to TCDD, which causes circulation failure including edema, craniofacial malformation culminating in mortality [24,

*Correspondence to: Teraoka, H.: hteraoka@rakuno.ac.jp (Supplementary material: refer to PMC https://www.ncbi.nlm.nih.gov/pmc/journals/2350/) (C2021 The Japanese Society of Veterinary Science

This is an open-access article distributed under the terms of the Creative Commons Attribution Non-Commercial No Derivatives (by-nc-nd) License. (CC-BY-NC-ND 4.0: https://creativecommons.org/licenses/by-nc-nd/4.0/) 
53, 54]. All of these defects in live eleutheroembryos (embryos and larvae) can be easily and noninvasively determined by using a conventional stereo or inverted microscope in a normal plastic dish for cell culture. Fish species including zebrafish have plural isoforms of AHR including AHR1a, AHR1b, and AHR2 as well as its heterodimerization partner AHR nuclear translocator including ARNT1 and ARNT2 [22]. Among these, AHR2/ARNT1 heterodimer mediates major parts of TCDD-evoked toxicity in larval fish $[1,12,45,46,55]$. However, the signaling pathways after AHR2/ARNT1 by TCDD are not always clear.

Unlike mammals, there are two inducible cyclooxygenase 2 (COX2) genes, COX2a and COX2b [13, 19] in zebrafish. Our previous study using a high-speed camera suggested the involvement of the COX2b-thromboxane pathway in TCDD-evoked pre-cardiac edema (early edema) in 55-hpf zebrafish eleutheroembryos, which could be the result of AHR2/ARNT1 activation [57]. TCDD-evoked early edema was almost blocked by both antioxidants and thromboxane receptor (TP) inhibitors [57]. We also showed that TP agonist-induced edema was antagonized by activation of the prostacyclin receptor (IP) but not by antioxidants [42]. These results suggest that both TP pathway and oxidative stress are involved in TCDD-induced circulation failure including edema, but the sites of their actions are different.

Nuclear factor erythroid 2-related factor $2(\mathrm{Nrf} 2)$ is a master regulator against oxidative stress, inducing antioxidant proteins, such as glutathione synthase or glutathione reductase as well as drug-metabolizing enzymes $[9,26]$. There are two Nrf2 proteins (Nrf2a and Nrf2b) $[25,38,58]$, two Keap1 proteins (Keap1a and Keap1b) [33, 41], and four small Maf proteins in zebrafish (MafGa, MafGb, MafK, and MafF) [52]. Recently, it was reported that PCB126, an AHR agonist, produced more severe pericardial edema in zebrafish with a mutated DNA binding domain in Nrf2a ( $\left.n f e 2 l 2 a^{f h 318 / f h 318}\right)$ without a notable effect on AHR2 expression [48].

We reported that TP agonist-induced early edema was much less severe than the effect by TCDD alone [42], implying the involvement of additional factors besides TP activation in TCDD-induced early edema. Thus, we investigated the effects of some oxidative stress inducers including paraquat and $\mathrm{H}_{2} \mathrm{O}_{2}$ besides rotenone [32] and activators of Nrf2 signaling on edema formation in developing zebrafish. We aimed to elucidate the possible interaction of oxidative stress and the AHR-mediated pathway.

\section{MATERIALS AND METHODS}

\section{Chemicals}

TCDD was purchased from Cambridge Isotope Laboratories. 2,3,3a,8b-Tetrahydro-2-hydroxy-1-(3-hydroxy-4-methyl-1-octen-6ynyl)-1H-cyclopenta[b]benzofuran-5-butanoic acid (beraprost) and 9,11-dideoxy-9 $\alpha, 11 \alpha$-methanoepoxy prosta-5Z-13E-dien-1-oic acid (U46619) were obtained from Cayman Chemical (Ann Arbor, MI, USA). 4-(Z)-6-(2-o-chlorophenyl-4-o-hydroxyphenyl1,3-dioxan-cis-5-yl) hexenoic acid) (ICI-192,605) and R, S-sulforaphane were purchased from Tocris Bioscience (Bristol, UK) and LKT Laboratories (St. Paul, MN, USA), respectively. Paraquat dichloride standard was obtained from FUJIFILM Wako Pure Chemical (Osaka, Japan). Auranofin was purchased from Tokyo Chemical Industry (Tokyo, Japan). All other chemicals were commercially available products of special reagent grade.

\section{Zebrafish and TCDD treatment}

Fertilized eggs were obtained from natural mating of adult zebrafish (Long-fin) in our laboratory. Adult fish and embryos were maintained at $28.5^{\circ} \mathrm{C}$ with a lighting schedule of 14-hr light and 10-hr dark. At $24 \mathrm{hr}$ after spawning, newly fertilized eggs were exposed to either a TCDD vehicle, dimethyl sulfoxide (DMSO, usually $0.1 \%$ ), or an apparent concentration of waterborne TCDD of 0.1 or 1.0 parts per billion (ppb) dissolved in $0.1 \%$ DMSO in $3 \mathrm{ml}$ of Zebrafish Ringer solution $(38.7 \mathrm{mM} \mathrm{NaCl}, 1.0 \mathrm{mM} \mathrm{KCl}$, $1.7 \mathrm{mM}$ HEPES-NaOH pH 7.2, $2.4 \mathrm{mM} \mathrm{CaCl}_{2}$ ) in $3.5 \mathrm{~cm}$ petri dishes (Asahi Techno Glass, Yoshida, Japan) for the duration of the experiment (10 embryos/dish). Beraprost $(10 \mu \mathrm{M})$ was included from $24 \mathrm{hpf}$. Ascorbic acid (10 mM) and $20 \mu \mathrm{M} \mathrm{N}$-acetylcysteine (NAC) were added at $33 \mathrm{hpf}$ and changed at $48 \mathrm{hpf}$ for consistent antioxidative effects. $\mathrm{NaOH}$ was added to ascorbic acid containing solution for $\mathrm{pH} 7.2$. Oxidative stress inducers, $100 \mu \mathrm{g} / \mathrm{ml}$ paraquat, $1.5 \mathrm{mM}$ hydrogen peroxide and $1.25 \mathrm{nM}$ rotenone were added $24 \mathrm{hpf}$ and newly changed at $48 \mathrm{hpf}$. Eleutheroembryos were challenged with $7.5 \mu \mathrm{M}$ U46619 and $24 \mu \mathrm{M}$ ICI-192,605 from 48 hpf, because longer exposure of U46619 caused yolk malformation [57]. Sulforaphane (40 $\mu \mathrm{M})$ and $2.5 \mu \mathrm{M}$ auranofin were included, beginning at $24 \mathrm{hpf}$ and $33 \mathrm{hpf}$, respectively, following our previous reports in which these Nrf2 activators were pretreated long before toxic compounds challenge [10,11].

\section{Measurement of edema}

Pre-cardiac edema (edema or early edema) was determined with a high-speed camera (1,000 images/sec) (LRH1601BL, Digimo, Tokyo, Japan) connected to an inverted microscope (DP70-IX71, Olympus, Tokyo, Japan), as previously described [57, Fig. 1 inset). The area of the small cavity between the heart and body wall at maximal diastole was quantified in pixels. Pre-cardiac edema was expressed as a percentage of the area of vehicle controls for normalization of edema in separate experiments.

\section{Real-time RT-PCR}

In order to study expression levels of cytochrome P450 1A (CYP1A) and COX2b, quantitative real-time RT-PCR (RT-qPCR) analysis was carried out [57]. Total RNA was extracted from larval zebrafish at $55 \mathrm{hpf}$ with TRI-reagent (Sigma-Aldrich, St. Louis, MO). cDNA was prepared from total RNA with ReverTra Ace qPCR RT Kit (Toyobo, Osaka, Japan). qRT-PCR analysis was performed in Real-Time PCR Detector (LightCycler 96: Roche Life Science, Penzberg, Germany) using Thunderbird qPCR mix containing SYBR Green (Toyobo). 

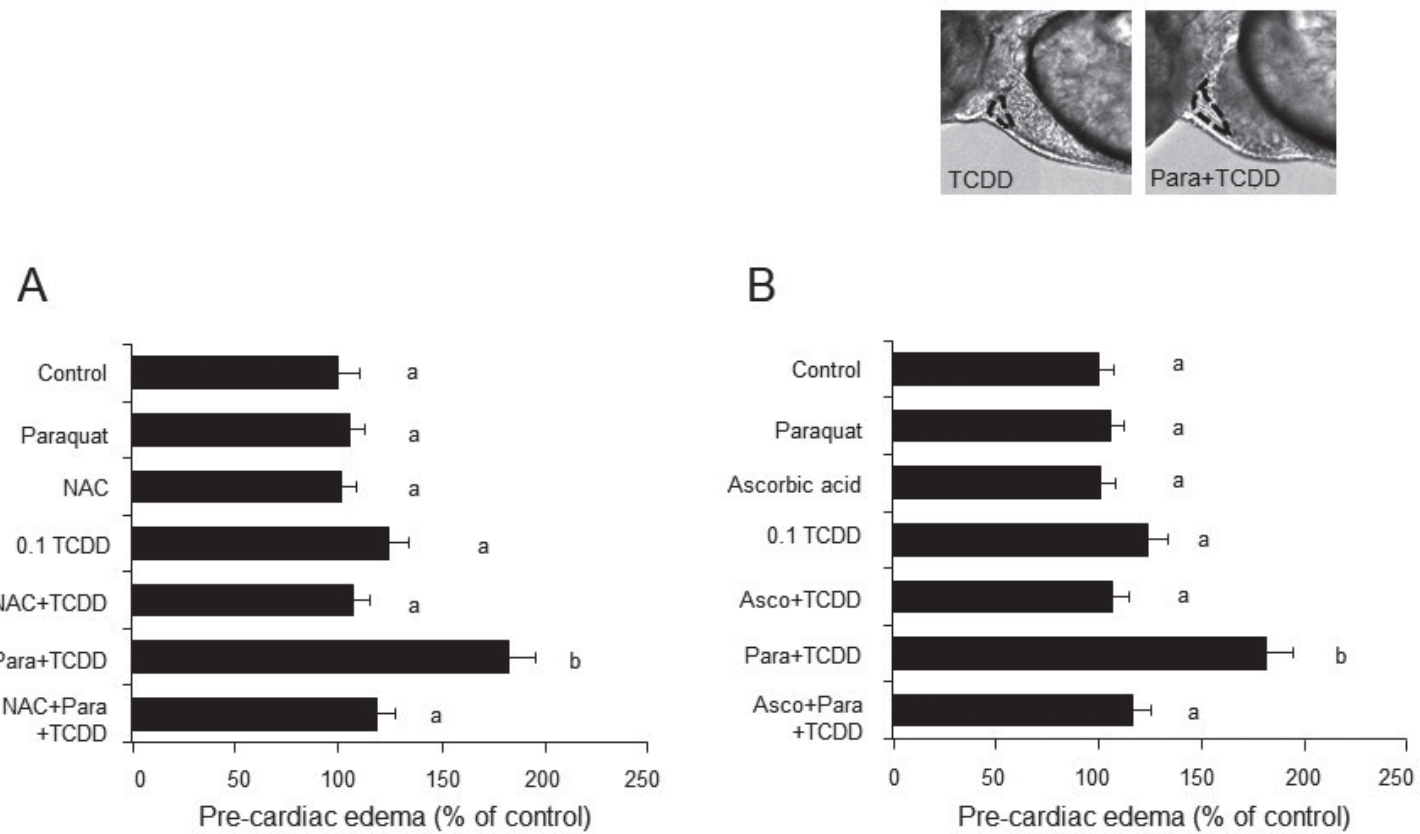

Fig. 1. Paraquat augments 2,3,7,8-tetrachlorodibenzo- $p$-dioxin-evoked pre-cardiac edema in an antioxidant-sensitive manner. Eleutheroembryos were treated with $0.1 \mathrm{ppb} 2,3,7,8$-tetrachlorodibenzo- $p$-dioxin $(0.1 \mathrm{TCDD}$ or TCDD) or a vehicle $(0.1 \% \mathrm{DMSO})(\mathrm{Control})$ beginning at 24 hpf. Paraquat (Para) (an oxidative stress inducer) (100 $\mu \mathrm{g} / \mathrm{ml}), 20 \mu \mathrm{M} \mathrm{N}$-acetylcysteine (NAC) (A), and $10 \mathrm{mM}$ ascorbic acid (Asco) (B) were also included in some cases. Chemicals were newly changed at 48 hpf. At 55 hpf, the area of the pre-cardiac cavity was determined as an index of TCDD-induced edema (pre-cardiac edema, dashed circles in insets). Results are expressed as percentage of the control (means \pm SEM, $\mathrm{n}=19-21)$. Values with different letters are significantly different $(P<0.05)$.

\section{Statistics}

Results are presented as means \pm SEM. Significant differences between the vehicle control and TCDD-exposed groups were determined by one-way ANOVA followed by the Tukey-Kramer test $(P<0.05)$. Student's $t$-test or Welch's test were also used to compare means of two groups after the $F$-test $(P<0.05)$.

\section{RESULTS}

\section{Effects of oxidative stress inducers on TCDD-induced edema}

A single application of paraquat $(100 \mu \mathrm{g} / \mathrm{ml}=389 \mu \mathrm{M})$ did not cause pre-cardiac edema (early edema or edema) by itself (Fig. 1). However, paraquat markedly augmented edema caused by $0.1 \mathrm{ppb}$ TCDD, which showed a marginal effect on edema formation alone (Fig. 1). As in the case with paraquat, other oxidative stress inducers, hydrogen peroxide $\left(\mathrm{H}_{2} \mathrm{O}_{2}, 1.5 \mathrm{mM}\right)[11]$ and rotenone (1.25 nM) [44], also showed augmentation of edema caused by $0.1 \mathrm{ppb}$ TCDD (Supplementary Fig. 1).

Antioxidants, N-acetylcystein (NAC, $20 \mu \mathrm{M}$ ) (Fig. 1A) and ascorbic acid (10 mM) (Fig. 1B), neither of which affected the basal level of edema by themselves, inhibited early edema induced by $0.1 \mathrm{ppb}$ TCDD in the presence of an oxidative stress inducer (paraquat). Early edema caused by TCDD plus paraquat was inhibited by either a TP antagonist (ICI-192,605, 24 $\mu$ M) or an IP agonist (beraprost, $10 \mu \mathrm{M}$ ) (Supplementary Fig. 2), while higher concentration of TCDD-induced edema was also antagonized by either a TP antagonist or an IP agonist $[42,56]$.

\section{Effects of Nrf2 activators on TCDD-induced edema}

It was reported that sulforaphane [40] and auranofin [11] activate Nrf2 signaling in developing zebrafish. Thus, the effects of these Nrf2 activators were investigated. Sulforaphane $(40 \mu \mathrm{M})$ (Fig. 2A) and auranofin $(2.5 \mu \mathrm{M})($ Fig. 2B) markedly inhibited 1.0 ppb TCDD-evoked edema without affecting the control level. Sulforaphane also abolished $0.1 \mathrm{ppb}$ TCDD-evoked edema in the presence of $100 \mu \mathrm{g} / \mathrm{ml}$ paraquat (Supplementary Fig. 3).

\section{Effects of paraquat on expressions of COX2b and CYP1A}

As it has been reported that paraquat induces COX2 in neuroblastoma cell line [66], we studied the effects of paraquat with RT-qPCR on expression of COX2b that is involved in TCDD-induced pre-cardiac edema in zebrafish [57].

As shown in Fig. 3, paraquat $(100 \mu \mathrm{g} / \mathrm{ml})$ did not affect COX2b expression at all irrespective of the presence or absence of lower concentration of TCDD $(0.1 \mathrm{ppb})$, although the same concentration of paraquat as in measurement of pre-cardiac edema was used. 
A

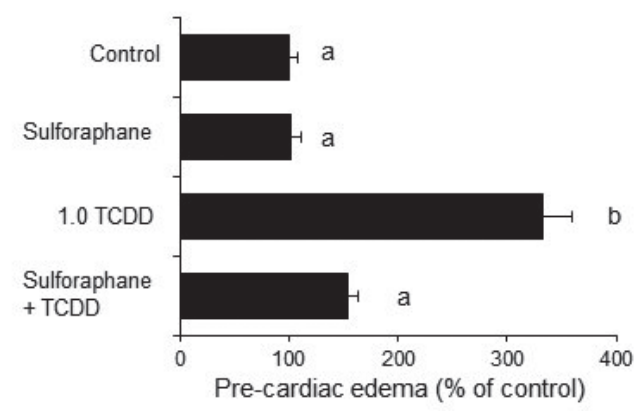

B

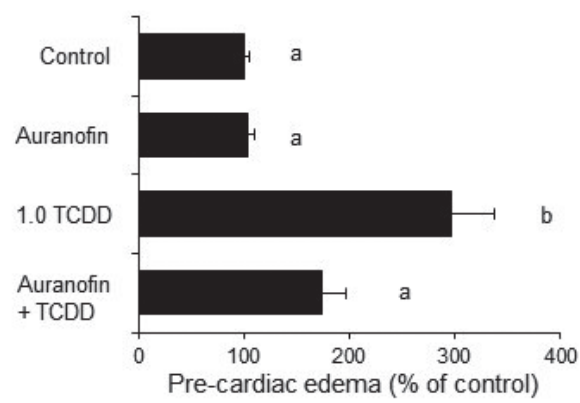

Fig. 2. Nuclear factor erythroid 2-related factor 2 (Nrf2) activators inhibit 2,3,7,8-tetrachlorodibenzo- $p$-dioxin-induced pre-cardiac edema. Eleutheroembryos were treated with $1.0 \mathrm{ppb}$ 2,3,7,8-tetrachlorodibenzo- $p$-dioxin (1.0 TCDD or TCDD) or a vehicle beginning at $24 \mathrm{hpf}$. Sulforaphane (40 $\mu \mathrm{M})(\mathrm{A})$ and $2.5 \mu \mathrm{M}$ auranofin (B) were also included, beginning at $24 \mathrm{hpf}$ and $33 \mathrm{hpf}$, respectively. Chemicals were newly changed at $48 \mathrm{hpf}$ and pre-cardiac cavity was evaluated at $55 \mathrm{hpf}$. Results are expressed as percentage of the control (means \pm SEM). $\mathrm{n}=18-21$ (A), $\mathrm{n}=20$ (B). Values with different letters are significantly different $(P<0.05)$.

A

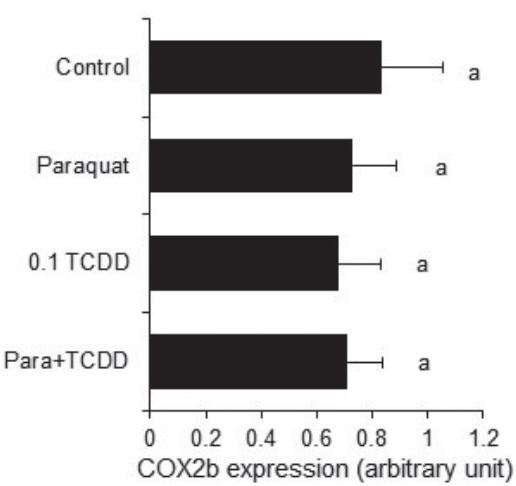

B

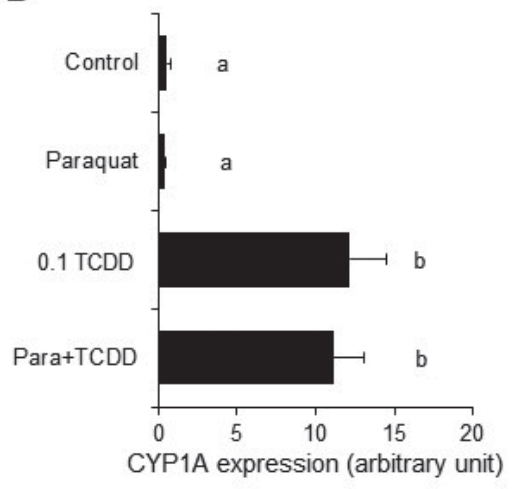

Fig. 3. No effects of paraquat on expression of cyclooxygenase 2 and cytochrome P450 1A expression. Paraquat (Para) $(100 \mu \mathrm{g} / \mathrm{ml})$ and $0.1 \mathrm{ppb}$ 2,3,7,8-tetrachlorodibenzo- $p$-dioxin (TCDD) (0.1 TCDD or TCDD) were applied from $24 \mathrm{hpf}$ and larvae were harvested at 55 hpf for RT-qPCR of cyclooxygenase 2b (COX2b) (A) and cytochrome P450 1A (CYP1A) (B). Chemicals were newly changed at 48 hpf. Results are expressed as arbitrary unit (means \pm SEM). $n=5$ (A, B). Values with different letters are significantly different $(P<0.05)$.

Similarly, paraquat was without effect on CYP1A expression, although CYP1A was markedly induced by even lower concentration of TCDD (0.1 ppb), suggesting no effects of paraquat on AHR2-CYP1A signaling.

\section{Effects of oxidative stress inducers on edema caused by a TP agonist}

Previously, we reported that U46619, a TP agonist caused pre-cardiac edema [57]. As in the case of TCDD, paraquat significantly augmented $7.5 \mu \mathrm{M}$ U46619-induced edema (Fig. 4). Both antioxidants, NAC (20 $\mu \mathrm{M})$ (Fig. 4A) and ascorbic acid $(10 \mathrm{mM})$ (Fig. 4B), inhibited early edema induced by U46619 in the presence of paraquat to the same level as that by U46619 alone. In contrast, neither NAC nor ascorbic acid at the concentrations used reduced edema that was caused by a single application of U46619. Similar to the case for TCDD, other oxidative stress inducers, $\mathrm{H}_{2} \mathrm{O}_{2}(1.5 \mathrm{mM})$ and rotenone $(1.25 \mathrm{nM})$, caused edema in the presence of a lower concentration of U46619 $(0.5 \mu \mathrm{M})$, which did not show a significant effect on edema by itself (Supplementary Fig. 4).

It was also confirmed that paraquat-induced pre-cardiac edema in the presence of a lower concentration of U46619 $(0.5 \mu \mathrm{M})$ was inhibited by ICI-192,605 (24 $\mu \mathrm{M})$ and beraprost $(10 \mu \mathrm{M})$ (Fig. 5).

\section{Effects of Nrf2 activators on edema caused by a TP agonist}

As shown in Fig. 6, sulforaphane $(40 \mu \mathrm{M})$ had no effect at all on edema induced by $7.5 \mu \mathrm{M}$ U46619. However, the same concentration of sulforaphane inhibited edema caused by U46619 plus $100 \mu \mathrm{g} / \mathrm{ml}$ paraquat to the level of edema evoked by U46619 alone (Fig. 6). 
A

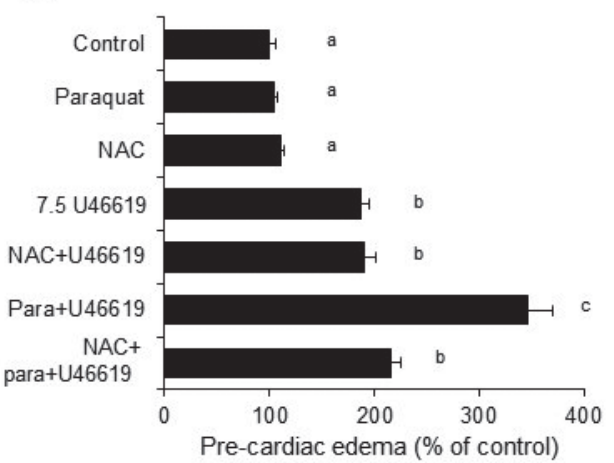

B

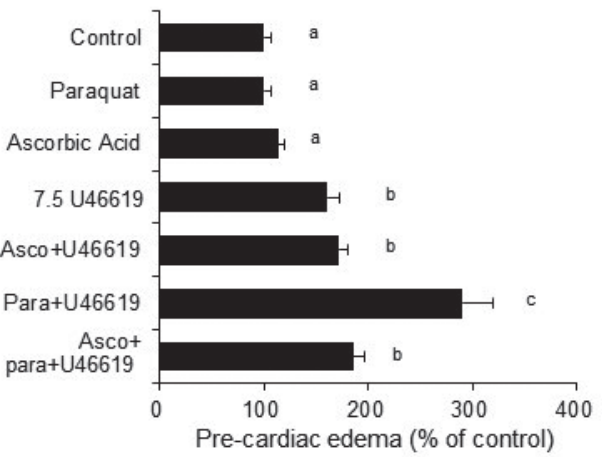

Fig. 4. Paraquat augments pre-cardiac edema caused by thromboxane receptor activation in an antioxidant-sensitive manner. Paraquat (Para) $(100 \mu \mathrm{g} / \mathrm{ml}), \mathrm{U} 46619(7.5 \mu \mathrm{M})(7.5 \mathrm{U})$ and N-acetylcystein (NAC) $(20 \mu \mathrm{M})(\mathrm{A})$, ascorbic acid (Asco) (10 mM) (B) were applied from $48 \mathrm{hpf}$ and pre-cardiac cavity was evaluated at $55 \mathrm{hpf}$. Results are expressed as percentage of the control (means $\pm \mathrm{SEM}) . \mathrm{n}=20$ (A), $\mathrm{n}=19-22$ (B). Values with different letters are significantly different $(P<0.05)$.

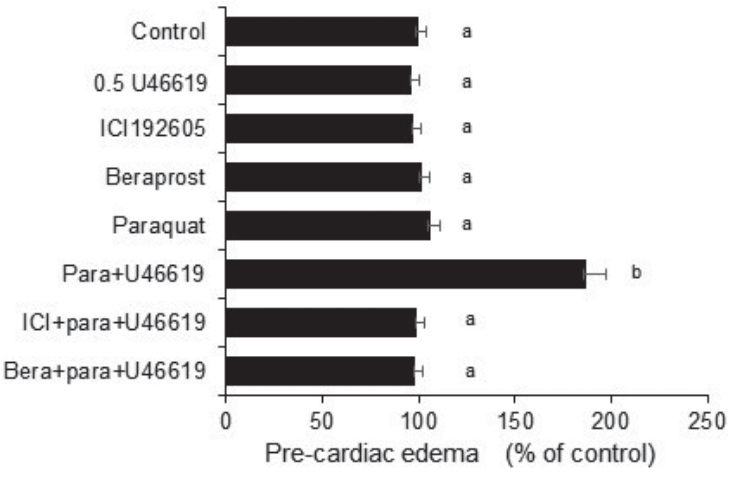

Fig. 5. Potentiation of thromboxane receptor agonist-induced pre-cardiac edema by an oxidative stress inducer was sensitive to a thromboxane receptor blocker and a prostacyclin receptor agonist. Paraquat (Para) $(100 \mu \mathrm{g} / \mathrm{ml})$, ICI-192,605 (ICI) $(24 \mu \mathrm{M})$, beraprost (Bera) $(10 \mu \mathrm{M}$,$) and U46619 (0.5$ $\mu \mathrm{M})$ were applied from $48 \mathrm{hpf}$ and pre-cardiac cavity was evaluated at $55 \mathrm{hpf}$. Results are expressed as percentage of the control (means $\pm \mathrm{SEM}) . \mathrm{n}=20$. Values with different letters are significantly different $(P<0.05)$.

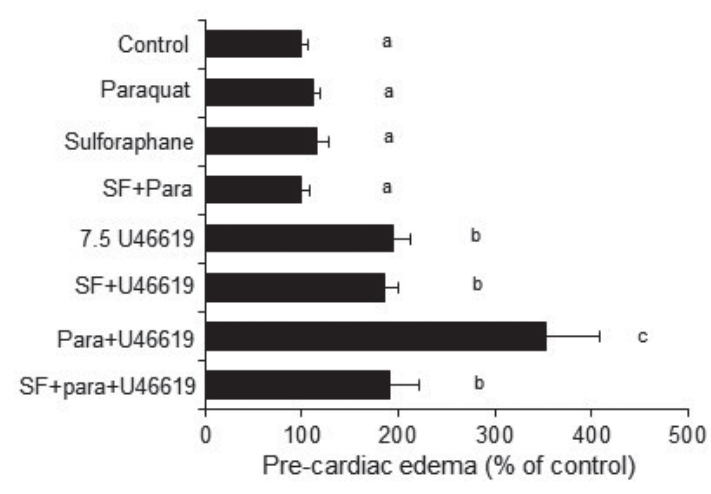

Fig. 6. A nuclear factor erythroid 2-related factor 2 inducer inhibits oxidative stress-induced augmentation of pre-cardiac edema by thromboxane receptor activation. U46619 $(7.5 \mu \mathrm{M})(7.5 \mathrm{U})$, paraquat (Para) $(100 \mu \mathrm{g} / \mathrm{ml})$ and sulforaphane $(40 \mu \mathrm{M})(\mathrm{SF})$ were applied from $48 \mathrm{hpf}$ and pre-cardiac cavity was evaluated at $55 \mathrm{hpf}$. Results are expressed as percentage of the control (means $\pm \mathrm{SEM}$, $\mathrm{n}=19-21)$. Values with different letters are significantly different $(P<0.05)$.

\section{DISCUSSION}

In the present study, paraquat and another oxidative stress inducers or oxidative stress itself, rotenone and $\mathrm{H}_{2} \mathrm{O}_{2}$, potentiated early edema induced by a lower concentration of TCDD without any major effect in control larvae, and the potentiation by these three chemicals was inhibited by two different antioxidants. These oxidative stress inducers are also an environmental contaminants as sources of oxidative stress $[60,69]$. Edema caused by TCDD plus paraquat was almost blocked by a TP antagonist and an IP agonist. These treatments also blocked edema caused by TCDD alone [42, 57], suggesting that the site of action of paraquat was in the regular signaling pathway after activation of AHR2 by TCDD. The involvement of oxidative stress in TCDD- or other DLCs-induced circulation failure in zebrafish and in other fish in development has been suggested by the experiments with antioxidants $[5,39,59]$. The results of the present study support the involvement of oxidative stress in TCDD-induced edema, using oxidative stress inducers and antioxidants. Liu et al. [34] directly detected oxidative stress by a reactive oxygen species (ROS)-sensitive fluorescent dye and by expression of EGFP linked to the Nrf2a promoter in larval zebrafish exposed to coplanar PCB. It has also been reported that malondialdehyde formation was significantly increased by TCDD and was decreased by some superoxide scavenging enzymes such as superoxide dismutase (SOD) in larval zebrafish [35]. On the other hand, however, Hahn et al. [14] found a small but significant induction of Nrf2a by TCDD but no induction of the target molecules of the Nrf2Keap1 system including glutathione S-transferase pi (GSTP1) and SOD in developing zebrafish. Thus, we should consider the 
possibility that TCDD cannot induce oxidative stress extensively but can only induce oxidative stress in localized fashion in larval zebrafish at least in the early stage. We observed that paraquat and other oxidative stress inducers caused significant edema in the presence of a very low concentration of TCDD, which did not cause edema at all by itself. This raise the possibility that oxidative stress caused by another source can evoke edema without application of TCDD or other AHR agonist, because there might be endogenous AHR agonists also in zebrafish [64]. However, the three oxidative stress inducers that we used did not cause any edema by themselves. The difference might reflect properties of endogenous AHR agonists that are distinct from those of TCDD or insufficient concentrations of those substances in larval zebrafish. In any case, oxidative stress can augment TCDD under threshold concentration for causing edema. Other than endogenous source of oxidative stress, paraquat, $\mathrm{H}_{2} \mathrm{O}_{2}$ and heavy metal that exist in aquatic environment as a source of oxidative stress [20] also may play a role in toxicological response by TCDD and other DLCs.

The source of oxidative stress caused by TCDD is not known in this study. It was reported that TCDD produces mitochondrial respiration-dependent reactive oxygen in the AHR-dependent manner [18, 51]. Alternatively, ROS are produced from uncoupling of CYP1A by co-planar PCB [50]. TCDD markedly induced transcripts of CYP1A and CYP1Cs in endothelial cells and other organs in developing zebrafish $[21,31,65]$. TCDD caused oxidative stress in primary human aortic endothelial cells by way of CYP1A1 induction [29]. Kopf et al. [30] reported TCDD-induced superoxide generation in the rat aorta and heart and reduction of acetylcholine-induced relaxation of vascular smooth muscle strips by TCDD, suggesting inactivation of acetylcholine-produced nitric oxide by superoxide anion. In zebrafish at 3 days post fertilization (dpf), however, co-exposure to a nitric oxide synthase inhibitor had no effect and co-exposure to a nitric oxide donor worsened pericardial edema caused by coplanar PCB [59]. Further studies on the relationship between nitric oxide and oxidative stress are required.

Paraquat needs oxygen $\left(\mathrm{O}_{2}\right)$ for the formation of ROS such as $\mathrm{H}_{2} \mathrm{O}_{2}$ and hydroxyl radical ('OH) [32]. In zebrafish, gills become completely functional at a relatively later stage of development (12 dpf) [47], and direct diffusion of $\mathrm{O}_{2}$ through the skin is a pivotal route in supplying $\mathrm{O}_{2}$ to the tissues until the gills become functional. Thus, it is conceivable that $\mathrm{O}_{2}$ demand might be low in developing zebrafish around $55 \mathrm{hpf}$. This might be one of the reasons why paraquat itself did not cause major toxicological effects. Indeed, even a very high concentration of paraquat $(600 \mathrm{mg} / \mathrm{l}=\mathrm{c} . \mathrm{a} .2 .3 \mathrm{mM})$ alone had no effect on the appearance of developing zebrafish by $5 \mathrm{dpf}[2]$.

COX2 is a kind of oxygenase and requires oxygen for its activity and oxidative stress can modify COX2 enzyme activity [8]. Paraquat and $\mathrm{H}_{2} \mathrm{O}_{2}$ induce COX2 in neuroblastoma cells or endothelial cells $[6,66]$. In developing zebrafish at 55 hpf, however, level of COX $2 b$ transcripts was not affected by paraquat, while we previously reported involvement of the COX $2 b$-thromboxane pathway in TCDD-induced early edema [56, 57]. Also, CYP1A, a marker of AHR2 signaling was not induced by paraquat. These results suggest that AHR2-COX2b pathway that could be involved in TCDD-induced pre-cardiac edema is not a target of potentiation of pre-cardiac edema by oxidative stress inducers.

Meanwhile, paraquat and other oxidative stress inducers also potentiated U46619-induced early edema in a manner sensitive to two different antioxidants, similar to low concentration of TCDD. Thus, it is indicated that TP or the subsequent process of TP activation might be involved in the potentiation of TCDD-induced edema by oxidative stress inducers. The mechanism for the potentiation of TP-induced edema by oxidative stress is unknown. In mammals, interaction of thromboxane and oxidative stress as well as interactions of other factors such as endothelin with thromboxane in both endothelial cells and other tissues have been shown through extensive studies on cardiovascular diseases including hypertension by diabetes [4]. Among them, it was hypothesized that TP stimulation augments the generation of ROS via PKC- $\zeta$-mediated NAD(P)H oxidase activation in bovine aortic endothelial cells [68]. However, this is unlikely because antioxidant treatment never reduced edema caused by single exposure to a TP agonist in developing zebrafish (Fig. 4). Conversely, oxidants generate isoprostane 8-iso-PGF2 $\alpha$ from arachidonic acid, which also stimulates TP directly [4]. Although we previously indicated the requirement of thromboxane synthase in edema caused by TCDD in developing zebrafish [57], complementary effects of both TP agonists and thromboxane synthase should also be considered. Oxidative stress induces maturation and stabilization of the TP protein possibly by intracellular translocation [62, 63]. It is well known that TP couples to Gq to activate phospholipase $\mathrm{A}_{2}$ for production of $\mathrm{IP}_{3}$ and release of Ca ${ }^{2+}$ from intracellular stores [23]. Furthermore, oxidative stress contributes to the modulation of several signaling pathways including pathways regulating MAP kinase and Akt/eNOS as well as calcium-dependent signaling, in relation to vascular permeability [4]. Cultured endothelial cells derived from zebrafish should be used to clarify the intracellular mechanisms [17].

The nuclear factor Nrf2 pathway plays an indispensable role against oxidative stress through regulation of gene expression of a series of antioxidants and detoxifying enzymes as a master regulator in vertebrates including zebrafish larvae [27]. We observed that sulforaphane [10] and auranofin [11], activators of Nrf2, clearly suppressed TCDD-induced edema in the presence or absence of paraquat, supporting further that oxidative stress could be involved in potentiating effects by three oxidative stress inducers as well as higher concentration of TCDD-induced edema. In relation to our findings, Rousseau et al. (2016) reported that PCB126, a coplanar PCB, produced more severe pericardial edema in $\mathrm{Nrf2a}{ }^{(-)}$zebrafish in later stage. Furthermore, sulforaphane also abolished the potentiating effect of paraquat on U46619 without affecting edema caused by U46619 alone in this study, thus providing additional evidence that TP or the subsequent process of TP activation could be a target of potentiation of TCDD-induced edema by oxidative stress inducers. Modulatory effects of Nrf2 on AHR2 and thromboxane signaling should be also studied in the future study [48, 49, 67].

In conclusion, the results of this study suggest that oxidative stress participates in edema formation caused by TCDD at least partially via activation of TP-mediated signaling (Supplementary Fig. 5). There might be a positive interaction between TP signaling and oxidative stress in the induction of edema. A complex mechanism involving several factors appears to be responsible for TCDD-induced edema formation and thus implies that TCDD toxicity could be blocked by a variety of chemicals. It is also 
suggested that oxidative stress can augment TCDD under threshold concentration to cause edema, while there are many sources of oxidative stress in aquatic environment including paraquat, $\mathrm{H}_{2} \mathrm{O}_{2}$ and heavy metals. However, the precise mechanism of the interaction between thromboxane and oxidative stress in relation to AHR signaling needs to be clarified further in the future possibly by using an in vitro system such as cultured endothelial cells in combination with developing zebrafish.

CONFLICT OF INTEREST. We have nothing to declare.

ACKNOWLEDGMENT. This study was supported by Grant-in-Aids for Scientific Research (MEXT/JSPS KAKENHI 14F03777 and 20K06416) (H.T.).

\section{REFERENCES}

1. Antkiewicz, D. S., Peterson, R. E. and Heideman, W. 2006. Blocking expression of AHR2 and ARNT1 in zebrafish larvae protects against cardiac toxicity of 2,3,7,8-tetrachlorodibenzo-p-dioxin. Toxicol. Sci. 94: 175-182. [Medline] [CrossRef]

2. Bretaud, S., Lee, S. and Guo, S. 2004. Sensitivity of zebrafish to environmental toxins implicated in Parkinson's disease. Neurotoxicol. Teratol. 26: 857-864. [Medline] [CrossRef]

3. Chistiakov, D. A., Orekhov, A. N. and Bobryshev, Y. V. 2015. Endothelial barrier and its abnormalities in cardiovascular disease. Front. Physiol. 6: 365. [Medline] [CrossRef]

4. Cohen, R. A. and Tong, X. 2010. Vascular oxidative stress: the common link in hypertensive and diabetic vascular disease. J. Cardiovasc. Pharmacol. 55: 308-316. [Medline] [CrossRef]

5. Dong, W., Teraoka, H., Tsujimoto, Y., Stegeman, J. J. and Hiraga, T. 2004. Role of aryl hydrocarbon receptor in mesencephalic circulation failure and apoptosis in zebrafish embryos exposed to 2,3,7,8-tetrachlorodibenzo-p-dioxin. Toxicol. Sci. 77: 109-116. [Medline] [CrossRef]

6. Eligini, S., Arenaz, I., Barbieri, S. S., Faleri, M. L., Crisci, M., Tremoli, E. and Colli, S. 2009. Cyclooxygenase-2 mediates hydrogen peroxideinduced wound repair in human endothelial cells. Free Radic. Biol. Med. 46: 1428-1436. [Medline] [CrossRef]

7. Fernandez-Salguero, P. M., Hilbert, O. M., Rudikoff, S., Ward, J. M. and Gonzalez, F. J. 1996. Aryl-hydrocarbon receptor-deficient mice are resistant to 2,3.7,8-tetrachlorodibenzo-p-dioxininduced toxicity. Toxicol. Appl. Pharmacol. 140: 173-179. [Medline] [CrossRef]

8. Fujimoto, Y., Uno, E. and Sakuma, S. 2004. Effects of reactive oxygen and nitrogen species on cyclooxygenase-1 and -2 activities. Prostaglandins Leukot. Essent. Fatty Acids 71: 335-340. [Medline] [CrossRef]

9. Fuse, Y. and Kobayashi, M. 2017. Conservation of the Keap1-Nrf2 System: an evolutionary journey through stressful space and time. Molecules 22: E436. [Medline] [CrossRef]

10. Fuse, Y., Nguyen, V. T. and Kobayashi, M. 2016. Nrf2-dependent protection against acute sodium arsenite toxicity in zebrafish. Toxicol. Appl. Pharmacol. 305: 136-142. [Medline] [CrossRef]

11. Fuse, Y., Endo, Y., Araoi, S., Daitoku, H., Suzuki, H., Kato, M. and Kobayashi, M. 2018. The possible repositioning of an oral anti-arthritic drug, auranofin, for Nrf2-activating therapy: the demonstration of Nrf2-dependent anti-oxidative action using a zebrafish model. Free Radic. Biol. Med. 115: 405-411. [Medline] [CrossRef]

12. Garcia, G. R., Bugel, S. M., Truong, L., Spagnoli, S. and Tanguay, R. L. 2018. AHR2 required for normal behavioral responses and proper development of the skeletal and reproductive systems in zebrafish. PLoS One 13: e0193484. [Medline] [CrossRef]

13. Grosser, T., Yusuff, S., Cheskis, E., Pack, M. A. and FitzGerald, G. A. 2002. Developmental expression of functional cyclooxygenases in zebrafish. Proc. Natl. Acad. Sci. USA 99: 8418-8423. [Medline] [CrossRef]

14. Hahn, M. E., McArthur, A. G., Karchner, S. I., Franks, D. G., Jenny, M. J., Timme-Laragy, A. R., Stegeman, J. J., Woodin, B. R., Cipriano, M. J. and Linney, E. 2014. The transcriptional response to oxidative stress during vertebrate development: effects of tert-butylhydroquinone and 2,3,7,8-tetrachlorodibenzo- $p$-dioxin. PLoS One 9: e113158. [Medline] [CrossRef]

15. Hennig, B., Petriello, M. C., Newsome, B. J., Perkins, J. T. and Liu, D. 2018. Antioxidant therapy against persistent organic pollutants and associated diseases. pp. 217-224. In: Nutritional Antioxidant Therapies: Treatments and Perspectives (Hussain, K., Gubory, A. I. and Laher, I. eds.), Springer, Berlin/Heidelberg.

16. Hill, A. J., Teraoka, H., Heideman, W. and Peterson, R. E. 2005. Zebrafish as a model vertebrate for investigating chemical toxicity. Toxicol. Sci. 86: 6-19. [Medline] [CrossRef]

17. Huang, H., Lindgren, A., Wu, X., Liu, N. A. and Lin, S. 2012. High-throughput screening for bioactive molecules using primary cell culture of transgenic zebrafish embryos. Cell Rep. 2: 695-704. [Medline] [CrossRef]

18. Hwang, H. J., Dornbos, P., Steidemann, M., Dunivin, T. K., Rizzo, M. and LaPres, J. J. 2016. Mitochondrial-targeted aryl hydrocarbon receptor and the impact of 2,3,7,8-tetrachlorodibenzo-p-dioxin on cellular respiration and the mitochondrial proteome. Toxicol. Appl. Pharmacol. 304: 121-132. [Medline] [CrossRef]

19. Ishikawa, T. O., Griffin, K. J., Banerjee, U. and Herschman, H. R. 2007. The zebrafish genome contains two inducible, functional cyclooxygenase-2 genes. Biochem. Biophys. Res. Commun. 352: 181-187. [Medline] [CrossRef]

20. Jia, R., Du, J., Cao, L., Feng, W., He, Q., Xu, P. and Yin, G. 2020. Chronic exposure of hydrogen peroxide alters redox state, apoptosis and endoplasmic reticulum stress in common carp (Cyprinus carpio). Aquat. Toxicol. 229: 105657. [Medline] [CrossRef]

21. Jönsson, M. E., Orrego, R., Woodin, B. R., Goldstone, J. V. and Stegeman, J. J. 2007. Basal and 3,3',4,4',5-pentachlorobiphenyl-induced expression of cytochrome P450 1A, 1B and 1C genes in zebrafish. Toxicol. Appl. Pharmacol. 221: 29-41. [Medline] [CrossRef]

22. Karchner, S. I., Franks, D. G. and Hahn, M. E. 2005. AHR1B, a new functional aryl hydrocarbon receptor in zebrafish: tandem arrangement of ahrlb and ahr2 genes. Biochem. J. 392: 153-161. [Medline] [CrossRef]

23. Kent, K. C., Collins, L. J., Schwerin, F. T., Raychowdhury, M. K. and Ware, J. A. 1993. Identification of functional PGH2/TxA2 receptors on human endothelial cells. Circ. Res. 72: 958-965. [Medline] [CrossRef]

24. King-Heiden, T. C., Mehta, V., Xiong, K. M., Lanham, K. A., Antkiewicz, D. S., Ganser, A., Heideman, W. and Peterson, R. E. 2012. Reproductive and developmental toxicity of dioxin in fish. Mol. Cell. Endocrinol. 354: 121-138. [Medline] [CrossRef]

25. Kobayashi, M., Itoh, K., Suzuki, T., Osanai, H., Nishikawa, K., Katoh, Y., Takagi, Y. and Yamamoto, M. 2002. Identification of the interactive interface and phylogenic conservation of the Nrf2-Keap1 system. Genes Cells 7: 807-820. [Medline] [CrossRef]

26. Kobayashi, M. and Yamamoto, M. 2005. Molecular mechanisms activating the Nrf2-Keap1 pathway of antioxidant gene regulation. Antioxid. Redox 
Signal. 7: 385-394. [Medline] [CrossRef]

27. Kobayashi, M. and Yamamoto, M. 2006. Nrf2-Keap1 regulation of cellular defense mechanisms against electrophiles and reactive oxygen species. Adv. Enzyme Regul. 46: 113-140. [Medline] [CrossRef]

28. Konukoglu, D. and Uzun, H. 2017. Endothelial Dysfunction and Hypertension. Adv. Exp. Med. Biol. 956: 511-540. [Medline] [CrossRef]

29. Kopf, P. G. and Walker, M. K. 2010. 2,3,7,8-tetrachlorodibenzo-p-dioxin increases reactive oxygen species production in human endothelial cells via induction of cytochrome P4501A1. Toxicol. Appl. Pharmacol. 245: 91-99. [Medline] [CrossRef]

30. Kopf, P. G., Scott, J. A., Agbor, L. N., Boberg, J. R., Elased, K. M., Huwe, J. K. and Walker, M. K. 2010. Cytochrome P4501A1 is required for vascular dysfunction and hypertension induced by 2,3,7,8-tetrachlorodibenzo-p-dioxin. Toxicol. Sci. 117: 537-546. [Medline] [CrossRef]

31. Kubota, A., Stegeman, J. J., Woodin, B. R., Iwanaga, T., Harano, R., Peterson, R. E., Hiraga, T. and Teraoka, H. 2011. Role of zebrafish cytochrome P450 CYP1C genes in the reduced mesencephalic vein blood flow caused by activation of AHR2. Toxicol. Appl. Pharmacol. 253: $244-252$. [Medline] [CrossRef]

32. Lascano, R., Muñoz, N., Robert, G., Rodriguez, M., Melchiorre, M., Trippi, V. and Quero, G. 2012. Paraquat: an oxidative stress inducer. pp. 135-148. In: Herbicides-Properties, Synthesis and Control of Weeds (Hasaneen, M. N. ed.), Intech, Winchester.

33. Li, L., Kobayashi, M., Kaneko, H., Nakajima-Takagi, Y., Nakayama, Y. and Yamamoto, M. 2008. Molecular evolution of Keap1. Two Keap1 molecules with distinctive intervening region structures are conserved among fish. J. Biol. Chem. 283: 3248-3255. [Medline] [CrossRef]

34. Liu, H., Gooneratne, R., Huang, X., Lai, R., Wei, J. and Wang, W. 2015. A rapid in vivo zebrafish model to elucidate oxidative stress-mediated PCB126-induced apoptosis and developmental toxicity. Free Radic. Biol. Med. 84: 91-102. [Medline] [CrossRef]

35. Liu, H., Nie, F. H., Lin, H. Y., Ma, Y., Ju, X. H., Chen, J. J. and Gooneratne, R. 2016. Developmental toxicity, oxidative stress, and related gene expression induced by dioxin-like PCB 126 in zebrafish (Danio rerio). Environ. Toxicol. 31: 295-303. [Medline] [CrossRef]

36. Liu, H., Shi, L., Giesy, J. P. and Yu, H. 2019. Polychlorinated diphenyl sulfides can induce ROS and genotoxicity via the AhR-CYP1A1 pathway. Chemosphere 223: 165-170. [Medline] [CrossRef]

37. Mimura, J., Yamashita, K., Nakamura, K., Morita, M., Takagi, T. N., Nakao, K., Ema, M., Sogawa, K., Yasuda, M., Katsuki, M. and FujiiKuriyama, Y. 1997. Loss of teratogenic response to 2,3,7,8-tetrachlorodibenzo-p-dioxin (TCDD) in mice lacking the Ah (dioxin) receptor. Genes Cells 2: 645-654. [Medline] [CrossRef]

38. Mukaigasa, K., Nguyen, L. T. P., Li, L., Nakajima, H., Yamamoto, M. and Kobayashi, M. 2012. Genetic evidence of an evolutionarily conserved role for Nrf2 in the protection against oxidative stress. Mol. Cell. Biol. 32: 4455-4461. [Medline] [CrossRef]

39. Na, Y. R., Seok, S. H., Baek, M. W., Lee, H. Y., Kim, D. J., Park, S. H., Lee, H. K. and Park, J. H. 2009. Protective effects of vitamin E against 3,3,4,4,5-pentachlorobiphenyl (PCB126) induced toxicity in zebrafish embryos. Ecotoxicol. Environ. Saf. 72: 714-719. [Medline] [CrossRef]

40. Nakajima, H., Nakajima-Takagi, Y., Tsujita, T., Akiyama, S., Wakasa, T., Mukaigasa, K., Kaneko, H., Tamaru, Y., Yamamoto, M. and Kobayashi, M. 2011. Tissue-restricted expression of Nrf2 and its target genes in zebrafish with gene-specific variations in the induction profiles. PLoS One 6 : e26884. [Medline] [CrossRef]

41. Nguyen, V. T., Bian, L., Tamaoki, J., Otsubo, S., Muratani, M., Kawahara, A. and Kobayashi, M. 2020. Generation and characterization of keaplaand keaplb-knockout zebrafish. Redox Biol. 36: 101667. [Medline] [CrossRef]

42. Nijoukubo, D., Tanaka, Y., Okuno, Y., Yin, G., Kitazawa, T., Peterson, R. E., Kubota, A. and Teraoka, H. 2016. Protective effect of prostacyclin against pre-cardiac edema caused by 2,3,7,8-tetrachlorodibenzo-p-dioxin and a thromboxane receptor agonist in developing zebrafish. Chemosphere 156: 111-117. [Medline] [CrossRef]

43. Peterson, R. E., Theobald, H. M. and Kimmel, G. L. 1993. Developmental and reproductive toxicity of dioxins and related compounds: crossspecies comparisons. Crit. Rev. Toxicol. 23: 283-335. [Medline] [CrossRef]

44. Polyak, E., Ostrovsky, J., Peng, M., Dingley, S. D., Tsukikawa, M., Kwon, Y. J., McCormack, S. E., Bennett, M., Xiao, R., Seiler, C., Zhang, Z. and Falk, M. J. 2018. N-acetylcysteine and vitamin E rescue animal longevity and cellular oxidative stress in pre-clinical models of mitochondrial complex I disease. Mol. Genet. Metab. 123: 449-462. [Medline] [CrossRef]

45. Prasch, A. L., Teraoka, H., Carney, S. A., Dong, W., Hiraga, T., Stegeman, J. J., Heideman, W. and Peterson, R. E. 2003. Aryl hydrocarbon receptor 2 mediates 2,3,7,8-tetrachlorodibenzo-p-dioxin developmental toxicity in zebrafish. Toxicol. Sci. 76: 138-150. [Medline] [CrossRef]

46. Prasch, A. L., Tanguay, R. L., Mehta, V., Heideman, W. and Peterson, R. E. 2006. Identification of zebrafish ARNT1 homologs: TCDD developmental toxicity in zebrafish requires ARNT1. Mol. Pharmacol. 69: 776-787. [Medline] [CrossRef]

47. Rombough, P. 2002. Gills are needed for ionoregulation before they are needed for $\mathrm{O}_{2}$ ) uptake in developing zebrafish, Danio rerio. J. Exp. Biol. 205: 1787-1794. [Medline] [CrossRef]

48. Rousseau, M. E., Sant, K. E., Borden, L. R., Franks, D. G., Hahn, M. E. and Timme-Laragy, A. R. 2015. Regulation of Ahr signaling by Nrf2 during development: effects of Nrf2a deficiency on PCB126 embryotoxicity in zebrafish (Danio rerio). Aquat. Toxicol. 167: 157-171. [Medline] [CrossRef]

49. Shaw, P. and Chattopadhyay, A. 2020. Nrf2-ARE signaling in cellular protection: Mechanism of action and the regulatory mechanisms. J. Cell. Physiol. 235: 3119-3130. [Medline] [CrossRef]

50. Schlezinger, J. J., Struntz, W. D., Goldstone, J. V. and Stegeman, J. J. 2006. Uncoupling of cytochrome P450 1A and stimulation of reactive oxygen species production by co-planar polychlorinated biphenyl congeners. Aquat. Toxicol. 77: 422-432. [Medline] [CrossRef]

51. Senft, A. P., Dalton, T. P., Nebert, D. W., Genter, M. B., Puga, A., Hutchinson, R. J., Kerzee, J. K., Uno, S. and Shertzer, H. G. 2002. Mitochondrial reactive oxygen production is dependent on the aromatic hydrocarbon receptor. Free Radic. Biol. Med. 33: 1268-1278. [Medline] [CrossRef]

52. Takagi, Y., Kobayashi, M., Li, L., Suzuki, T., Nishikawa, K. and Yamamoto, M. 2004. MafT, a new member of the small Maf protein family in zebrafish. Biochem. Biophys. Res. Commun. 320: 62-69. [Medline] [CrossRef]

53. Tanguay, R. L., Andreasen, E. A., Walker, M. K. and Peterson, R. E. 2003. Dioxin toxicity and aryl hydrocarbon receptor signaling in fish. pp. 603-628. In: Dioxins and Health, 2nd ed. (Schecter, A. and Gasiewicz, T. A. eds.), John Wiley \& Sons, Inc., New York.

54. Teraoka, H., Dong, W. and Hiraga, T. 2003a. Zebrafish as a novel experimental model for developmental toxicology. Congenit. Anom. (Kyoto) 43: 123-132. [Medline] [CrossRef]

55. Teraoka, H., Dong, W., Tsujimoto, Y., Iwasa, H., Endoh, D., Ueno, N., Stegeman, J. J., Peterson, R. E. and Hiraga, T. 2003b. Induction of cytochrome P450 1A is required for circulation failure and edema by 2,3,7,8-tetrachlorodibenzo-p-dioxin in zebrafish. Biochem. Biophys. Res. Commun. 304: 223-228. [Medline] [CrossRef]

56. Teraoka, H., Kubota, A., Dong, W., Kawai, Y., Yamazaki, K., Mori, C., Harada, Y., Peterson, R. E. and Hiraga, T. 2009. Role of the cyclooxygenase 2-thromboxane pathway in 2,3,7,8-tetrachlorodibenzo- $p$-dioxin-induced decrease in mesencephalic vein blood flow in the zebrafish embryo. Toxicol. Appl. Pharmacol. 234: 33-40. [Medline] [CrossRef]

57. Teraoka, H., Okuno, Y., Nijoukubo, D., Yamakoshi, A., Peterson, R. E., Stegeman, J. J., Kitazawa, T., Hiraga, T. and Kubota, A. 2014. Involvement of COX2-thromboxane pathway in TCDD-induced precardiac edema in developing zebrafish. Aquat. Toxicol. 154: 19-26. [Medline] [CrossRef] 
58. Timme-Laragy, A. R., Karchner, S. I., Franks, D. G., Jenny, M. J., Harbeitner, R. C., Goldstone, J. V., McArthur, A. G. and Hahn, M. E. 2012. Nrf2b, novel zebrafish paralog of oxidant-responsive transcription factor NF-E2-related factor 2 (NRF2). J. Biol. Chem. 287: 4609-4627. [Medline] [CrossRef]

59. Teixidó, E., Barenys, M., Piqué, E., Llobet, J. M. and Gómez-Catalán, J. 2019. Cardiovascular Effects of PCB 126 (3,3',4,4',5-Pentachlorobiphenyl) in zebrafish embryos and empact of co-exposure to redox modulating chemicals. Int. J. Mol. Sci. 20: E1065. [Medline] [CrossRef]

60. Ueki, R., Imaizumi, Y., Iwamoto, Y., Sakugawa, H. and Takeda, K. 2020. Factors controlling the degradation of hydrogen peroxide in river water, and the role of riverbed sand. Sci. Total Environ. 716: 136971. [Medline] [CrossRef]

61. Uemura, H., Arisawa, K., Hiyoshi, M., Kitayama, A., Takami, H., Sawachika, F., Dakeshita, S., Nii, K., Satoh, H., Sumiyoshi, Y., Morinaga, K., Kodama, K., Suzuki, T., Nagai, M. and Suzuki, T. 2009. Prevalence of metabolic syndrome associated with body burden levels of dioxin and related compounds among Japan's general population. Environ. Health Perspect. 117: 568-573. [Medline] [CrossRef]

62. Valentin, F., Field, M. C. and Tippins, J. R. 2004. The mechanism of oxidative stress stabilization of the thromboxane receptor in COS-7 cells. $J$. Biol. Chem. 279: 8316-8324. [Medline] [CrossRef]

63. Wilson, S. J., Cavanagh, C. C., Lesher, A. M., Frey, A. J., Russell, S. E. and Smyth, E. M. 2009. Activation-dependent stabilization of the human thromboxane receptor: role of reactive oxygen species. J. Lipid Res. 50: 1047-1056. [Medline] [CrossRef]

64. Wincent, E., Kubota, A., Timme-Laragy, A., Jönsson, M. E., Hahn, M. E. and Stegeman, J. J. 2016. Biological effects of 6-formylindolo[3,2-b] carbazole (FICZ) in vivo are enhanced by loss of CYP1A function in an Ahr2-dependent manner. Biochem. Pharmacol. 110-111: 117-129. [Medline] [CrossRef]

65. Yamazaki, K., Teraoka, H., Dong, W., Stegeman, J. J. and Hiraga, T. 2002. cDNA cloning and expressions of cytochrome P450 1A in zebrafish embryos. J. Vet. Med. Sci. 64: 829-833. [Medline] [CrossRef]

66. Yang, W., Tiffany-Castiglioni, E., Lee, M. Y. and Son, I. H. 2010. Paraquat induces cyclooxygenase-2 (COX-2) implicated toxicity in human neuroblastoma SH-SY5Y cells. Toxicol. Lett. 199: 239-246. [Medline] [CrossRef]

67. Yaekashiwa, M. and Wang, L. H. 2003. Nrf2 regulates thromboxane synthase gene expression in human lung cells. DNA Cell Biol. $22: 479-487$. [Medline] [CrossRef]

68. Zhang, M., Song, P., Xu, J. and Zou, M. H. 2011. Activation of NAD(P)H oxidases by thromboxane $\mathrm{A}_{2}$ receptor uncouples endothelial nitric oxide synthase. Arterioscler. Thromb. Vasc. Biol. 31: 125-132. [Medline] [CrossRef]

69. Zheng, F., Gonçalves, F. M., Abiko, Y., Li, H., Kumagai, Y. and Aschner, M. 2020. Redox toxicology of environmental chemicals causing oxidative stress. Redox Biol. 34: 101475. [Medline] [CrossRef] 